\title{
Transcriptome analysis of ovary culture-induced embryogenesis in cucumber (Cucumis sativus L.)
} \author{
Ji Li ${ }^{1}$, Jinfeng Chen ${ }^{\text {Corresp. } 1}$ \\ ${ }^{1}$ State Key Laboratory of Crop Genetics and Germplasm Enhancement, Nanjing Agricultural University, Nanjing, China \\ 2 Institute of Horticulture, Guizhou Academy of Agricultural Sciences, Guiyan, China \\ Corresponding Author: Jinfeng Chen \\ Email address: jfchen@njau.edu.cn
}

Ying Deng Equal frrst author, 1, 2 , Wenyuan Fu ${ }^{\text {Equal first author, }{ }^{2}, \text { Bing Tang }^{2}, \text { Lian Tao }^{2} \text {, Lu Zhang }}{ }^{1}$, Xia Zhou ${ }^{1}$, Qingqing Wang ${ }^{2}$,

Background. Ovary culture is a useful technique used to generate double haploid (DH) cucumber (Cucumis sativus L.) plants. However, cucumber ovary culture have a low rate of embryo induction and plant regeneration. Moreover, the cucumber embryogenesis mechanism remains unclear. In this study, we explored the molecular basis of cucumber embryogenesis in order to establish a foundation for a more efficient ovary culture method. Using transcriptome sequencing, we also investigated the differentially expression of genes during the embryogenesis process. Methods. Cytological and morphological observations have divided cucumber ovary culture into three stages: early embryo development (T0), embryo morphogenesis (T1, T2, T3, and T4), and shoot formation (T5). We selected six key time points for transcriptome sequencing and analysis: T0 (the ovules were cultured for $0 \mathrm{~d}$ ), T1 (the ovules were cultured for $2 \mathrm{~d}$ ), T2 (the embryos were cultured for $10 \mathrm{~d}$ ), T3 (the embryos were cultured for $20 \mathrm{~d}$ ), T4 (the embryos were cultured for $30 \mathrm{~d}$ ), and T5 (the shoots after $60 \mathrm{~d}$ culture). Results. We used cytology and morphology to observe the characteristics of the cucumber's developmental transformation during embryogenesis and plant regeneration. The differentially expressed genes(DEGs) at developmental transition points were analyzed using transcriptome sequencing. In the early embryogenesis stage, the cells expanded, which was the signal for gametophytes to switch to the sporophyte development pathway. RNA-seq revealed that when compared to the fresh unpollinated ovaries, there were 3,468 upregulated genes in the embryos, including hormone signal transduction genes, hormone response genes, and stress-induced genes. The reported embryogenesis-related genes BBM, HSP90, and $A G L$ were also actively expressed during this stage. In the embryo morphogenesis stage (from cell division to cotyledon-embryo formation), 480 genes that functioned in protein complex binding, microtubule binding, tetrapyrrole binding, tubulin binding and other microtubule activities were continuously upregulated during the T1, T2, T3, and T4 
time points. This indicated that the cytoskeleton structure was continuously being built and maintained by the action of microtubule-binding proteins and enzyme modification. In the shoot formation stage, 1,383 genes were upregulated that were mainly enriched in phenylpropanoid biosynthesis, plant hormone signal transduction, phenylalanine metabolism, and starch and sucrose metabolism. These upregulated genes included six transcription factors that contained a B3 domain, nine genes in the AP2/ERF family, and two genes encoding WUS homologous domain proteins. Conclusions. Evaluation of molecular gynogenesis events may contribute to a better understanding of the molecular mechanism of cucumber ovarian culture. 
1 Transcriptome analysis of ovary culture-induced embryogenesis in cucumber

2

3

4 Ying Deng ${ }^{1,2 \dagger}$, Wenyuan $\mathrm{Fu}^{2 \dagger}$, Bing Tang ${ }^{2}$, Lian $\mathrm{Tao}^{2}$, Lu Zhang ${ }^{1}$, Xia Zhou ${ }^{1}$ Qingqing Wang ${ }^{2}, \mathrm{Ji} \mathrm{Li}^{1}$ and

5 Jinfeng Chen ${ }^{1 *}$

6

$7{ }^{1}$ State Key Laboratory of Crop Genetics and Germplasm Enhancement, Nanjing Agricultural University,

8 Nanjing, China

$9 \quad 2$ Institute of Horticulture, Guizhou Academy of Agricultural Sciences, Guiyang, China

10

11

(Cucumis sativus L.)

$\dagger$ These authors contributed equally to this work.

*Please address all correspondence to: J F Chen (jfchen@njau.edu.cn)

Dr. Jin-Feng Chen

Professor

State Key Laboratory of Crop Genetics and Germplasm Enhancement,

Nanjing Agricultural University

Nanjing, China

E-mail:jfchen@njau.edu.cn

\section{Abstract}

Background. Ovary culture is a useful technique used to generate double haploid (DH) cucumber (Cucumis sativus L.) plants. However, cucumber ovary culture have a low rate of embryo induction and plant regeneration. Moreover, the cucumber embryogenesis mechanism remains unclear. In this study, we explored the molecular basis of cucumber embryogenesis in order to establish a foundation for a more efficient ovary culture method. Using transcriptome sequencing, we also investigated the differentially expression of genes during the embryogenesis process.

Methods. Cytological and morphological observations have divided cucumber ovary culture into three stages: early embryo development (T0), embryo morphogenesis (T1, T2, T3, and T4), and shoot formation (T5). We selected six key time points for transcriptome sequencing and analysis: 
31 T0 (the ovules were cultured for $0 \mathrm{~d}$ ), T1 (the ovules were cultured for $2 \mathrm{~d}$ ), T2 (the embryos 32 were cultured for $10 \mathrm{~d}$ ), T3 (the embryos were cultured for $20 \mathrm{~d}$ ), T4 (the embryos were cultured 33 for $30 \mathrm{~d}$ ), and $\mathrm{T} 5$ (the shoots after $60 \mathrm{~d}$ culture).

34 Results. We used cytology and morphology to observe the characteristics of the cucumber's developmental transformation during embryogenesis and plant regeneration. The differentially expressed genes(DEGs) at developmental transition points were analyzed using transcriptome sequencing. In the early embryogenesis stage, the cells expanded, which was the signal for gametophytes to switch to the sporophyte development pathway. RNA-seq revealed that when compared to the fresh unpollinated ovaries, there were 3,468 up-regulated genes in the embryos, including hormone signal transduction genes, hormone response genes, and stress-induced genes. The reported embryogenesis-related genes $B B M$, $H S P 90$, and $A G L$ were also actively expressed during this stage. In the embryo morphogenesis stage (from cell division to cotyledon-embryo formation), 480 genes that functioned in protein complex binding, microtubule binding, tetrapyrrole binding, tubulin binding and other microtubule activities were continuously up-regulated during the T1, T2, T3, and T4 time points. This indicated that the cytoskeleton structure was continuously being built and maintained by the action of microtubule-binding proteins and enzyme modification. In the shoot formation stage, 1,383 genes were up-regulated that were mainly enriched in phenylpropanoid biosynthesis, plant hormone signal transduction, phenylalanine metabolism, and starch and sucrose metabolism. These up-regulated genes included six transcription factors that contained a B3 domain, nine genes in the AP2/ERF family, and two genes encoding WUS homologous domain proteins.

52 Conclusions. Evaluation of molecular gynogenesis events may contribute to a better understanding of the molecular mechanism of cucumber ovarian culture.

Key words: Cucumber; Ovary culture; Embryogenesis; Transcriptome; Differentially expressed 55 genes 


\section{Introduction}

57 Gametophyte cultures involve the stress-induced reprogramming of male or female

58 gametophytes that develop into embryo-like structures and can be directly regenerated into

59 completely homozygous, doubled haploid (DH) plants. The study of male gametophyte (microspore) embryogenesis began in the 1960s (Guha et al., 1964). In vitro microspore embryogenesis can be easily monitored and provide a convenient experimental platform for large-scale physiological and biochemical analyses (Malik et al., 2007). However, the study of gynogenesis is more complicated. The embryo sac is small and embedded in the surrounding tissues, making early embryos difficult to observe and isolate. For plants that are recalcitrant to androgenesis (e.g., male-sterile and dioecious plants), gynogenesis is worthwhile (Pazuki et al. 2018). In vitro gynogenesis has mainly been used on the Cucurbitaceae, and previous studies have revealed that this technique is still imperfect with a low embryogenesis rate (Metwally et al., 1998; Gémes et al., 2002; Shalaby, 2007; Diao et al., 2009; Li et al., 2013; Plapung et al., 2014; Tantasawat, 2015). The study of the embryogenesis mechanism has therefore remained unexplored, and the understanding of the mechanisms underlying gynogenesis is extremely limited.

In general, embryogenesis induction using in vitro culture is a stress-induced phenomenon. Microspores are cultured and develop into embryos in vitro, and stress treatments involving cold shock, heat shock or hormones are used as trigger factors to induce gametocytes to follow the sporophyte development pathway (Touraev et al., 1997). The genes associated with the reprogramming phase and the early stage of embryogenesis were successfully characterized and include AGAMOUS-LIKE15-related (AGL15-related) genes and the AGAMOUS-LIKE15 (AGL15) gene, the BABY BOOM (BBM) gene, and the HEAT SHOCK PROTEIN (HSP) genes (Perry et al.,1999; Boutilier et al., 2002; Maraschin, 2005). Recently, functional genomics has made it possible to identify more genes associated with different microspore embryogenesis stages. When analyzing in vitro microspore cultures of Brassica napus, it was found that genes related to embryogenesis, such as $B B M 1, L E C 1$, and $L E C 2$, were expressed as early as 2-3 days after microspore culture. While embryogenesis was clearly established by $7 \mathrm{~d}$ of culture, the genes that were specifically expressed included ABSCISIC ACID INSENSITIVE3, ATS1, LEC1, LEC2, and FUSCA3 (Malik et al., 2007). Genes expression associated with metabolism, chromosome remodeling, transcription, and translation signaling was up-regulated during the 
87

stress treatment stage in tobacco (Hosp et al., 2007). Similarly, genes related to metabolism, cell wall, cell membrane, cell tissue control, cell communication, and signal transduction were detected in the early stage of rape embryogenesis (Rosa Angélica et al., 2013). High levels of $B B M$ and $L E C$ gene expression were confirmed in the early embryonic development of sweet pepper anther cultures (Irikova et al., 2012). The transition from microspores to developing embryos is mainly manifested in the induction of transcription factor genes that play an important role in early embryogenesis. Many genes involved in hormone biosynthesis and plant hormone signal transduction are additionally involved in secondary metabolism (Bélanger et al., 2018). Studies have shown that differentially expressed genes (DEGs) can be detected by gene chips in an early stage of the cucumber's in vitro gynogenesis, suggesting that phenylalanine metabolism and synthesis may play an important role in the early in vitro development of cucumber in vitro (Zhang et al., 2013).

Cucumber (Cucumis sativus L.) is the fourth most important vegetable worldwide (Lv et al., 2012), and accounted for more than 2.2 million hectares and a total production of approximately 83 million tons in 2017 (http://www.fao.org/faostat). Cucumber is one of the oldest vegetable crops and was domesticated in China approximately 2,000 years ago (Golabadi et al., 2012). To meet the needs of production, breeders are constantly looking for valuable germplasm characteristics, particularly resistance to disease and environmental stresses such as cold, drought, and salt (Wang et al., 2018). Although collecting extensive germplasm resources for variety improvements can greatly facilitate these breeding efforts, cucumber is a cross-pollinated plant with clear heterosis. Therefore, almost all of the cucumber varieties currently in production are hybrids with slow breeding processes. Breeding parents takes 6-8 years of artificial self-breeding in order to develop a stable inbred line. To accelerate the purification of cucumber parents and improve breeding efficiency, haploid gametophyte cultures can be used to induce embryoids, since homozygous DH plants can be obtained in 1-2 years. DH technology is a powerful tool used to speed up plant breeding. However, additional research is needed to improve our understanding of genes and their roles in embryogenesis and haploid induction mechanism in embryo sacs (Chen et al., 2011).

This study focused on the cucumber's highly efficient in vitro ovary culture technology system. We divided the process from acquiring embryogenic potential to plant regeneration into three stages: early embryo development, embryo morphogenesis (from pro-embryos to cotyledon embryos), and shoot formation. Via ovary culture, we evaluated the embryo morphology and 
119

120

121

122

123

124

125

126

127

128

129

130

131

132

133

134

135

136

137

138

139

140

141

142

143

144

145

146

147

148

149

transcriptomes across different developmental stages during cucumber embryogenesis. The metabolic and biological process of embryogenesis in the cucumber gynogenesis are discussed, and several key genes that regulated embryogenesis were identified.

\section{Materials and methods}

\section{Plant materials}

We used the $F_{1}$ cultivar 'SG033' ( http://kunming056278.11467.com/) for ovary culture because this material has a high embryo generation rate even after many screenings. Cucumber plants from southern China were cultivated and stored in our lab. The plant growth protocol was slightly adapted from Li et al. (2014). Specifically, the plants were grown in 12-hour photoperiod greenhouse at the Horticulture Institute of Guizhou Academy of Agricultural Sciences, Guizhou, China, with an average daily air temperature of $25 / 15^{\circ} \mathrm{C}$ (day/night), a relative humidity of $85 \%$, and a photosynthetic luminous flux density of $500 \mu \mathrm{mol} \cdot \mathrm{m}^{-2} \cdot \mathrm{s}^{-1}$. We collected ovaries from 'SG033' after the first anthesis flower appeared.

\section{Culture medium composition}

For MS medium, we used a basal medium that was supplemented with $0.06 \mathrm{mg} \cdot \mathrm{L}^{-1}$ thidiazuron (TDZ, Solarbio, Beijing, China) and 3\% (w/v) sucrose, and was solidified with $7 \%(\mathrm{w} / \mathrm{v})$ agar. The medium $\mathrm{pH}$ was adjusted to 5.9 before autoclaving at $116^{\circ} \mathrm{C}$ and $1.1 \mathrm{~kg} / \mathrm{cm}^{2}$ for $30 \mathrm{~min}$.

\section{Ovary culture}

Ovaries were harvested $6 \mathrm{~h}$ before anthesis, and were treated for $24 \mathrm{~h}$ in a refrigerator at $4{ }^{\circ} \mathrm{C}$. We removed their fruit tumor, sterilized with $75 \%$ ethanol for $30-60 \mathrm{~s}$, and them rinsed in sterile distilled water three times, soaked in a $0.5 \%$ sodium hypochlorite for $20 \mathrm{~min}$, and then rinsed them in sterile distilled water three times. The ovaries were cut into small round 2-mm slices under sterile conditions and placed on $30 \mathrm{~mL}$ of solid media in cylindrical flasks. All materials were treated with a high temperature of $33{ }^{\circ} \mathrm{C}$ for $2 \mathrm{~d}$, after which recovery growth was allowed until shoot formation occurred at $25{ }^{\circ} \mathrm{C}$ under a 16/8 h (light/dark) photoperiod with a 4,000-lux light intensity.

\section{Observation}

We observed embryo development according to the methods previously published by our team (Deng et al., 2020). Specifically, SG033 explants (varian fragments) were collected before and 
150 after culture, and resin sections were obtained to observe early, embryo development. Fifty 151 explants were collected separately at $0 \mathrm{~d}$ and $2 \mathrm{~d}$ fixed in formalin-acetic acid-alcohol ( $5 \mathrm{ml}$ of

152 formalin with $38 \%$ formaldehyde, $5 \mathrm{ml}$ of glacial acetic acid, and $90 \mathrm{ml}$ of $70 \%$ ethanol) (FAA)

153 at room temperature for $48 \mathrm{~h}$, dehydrated with a graded ethanol series, and then embedded in the 154 spur resin. Nine-micrometer-thick sections were stained with safranine and fast green, and were 155 observed using a biological microscope (Leica DM2500, Wetzlar, Germany). After $10 \mathrm{~d}$ of 156 culture, we evaluated the embryonic morphology using a stereo microscope (Leica M165 C, 157 Wetzlar, Germany).

\section{RNA isolation}

159

160

161

162

163

164

165

The materials were harvested separately at the following time points: T0 (the fresh unpollinated ovaries were cultured for $0 \mathrm{~d}$ ), T1 (the ovules were cultured for $2 \mathrm{~d}$ ), T2 (the embryos were cultured for $10 \mathrm{~d}$ ), T3 (the embryos were cultured for $20 \mathrm{~d}$ ), T4 (the embryos were cultured for $30 \mathrm{~d}$ ), and T5 (the shoots after $60 \mathrm{~d}$ of culture). We extracted ovules at T0 and T1 time points by hand under a stereo microscope, directly selected embryos at the time points from T2 to T4, and selected the shoots from T5. We used $200 \mathrm{mg}$ for each sample as the starting material for the RNAseq and qPCR experiments.

These materials were stored at $-80{ }^{\circ} \mathrm{C}$ for subsequent RNA extraction, and the remaining materials were maintained in culture in order to observe plantlet regeneration. All further experimental procedures, such as culture medium replacement and sample collection, were performed under similar conditions to minimize possible circadian effects.

As described above, we collected samples from six ovary culture time points for RNA-seq analysis. For each sample, the ovules or embryo-like structures were immersed in liquid nitrogen in a mortar and were ground into powder (three biological replicates per sample). Total RNA was isolated using TRIzol (Invitrogen, Carlsbad, CA, USA), and DNase I (Fermentas, Waltham, MA, USA) digestion was then performed for $30 \mathrm{~min}$ at $25{ }^{\circ} \mathrm{C}$ to remove DNA, according to the manufacturer's instructions. We determined the integrity and quality of the total RNA using a NanoDrop 1000 spectrophotometer and formaldehyde-agarose gel electrophoresis. RNA was used only when the $\mathrm{OD}_{260}: \mathrm{OD}_{280}$ ratio was above 1.8 .

The total RNA concentration for all of the samples was $\geqslant 80 \mathrm{ng} / \mu \mathrm{l}$, the OD: $260 / 280>2$, 260/230>2, and the rin value was close to 8.0 (see Fig. 1 for a agarose gel electrophoresis), 
180

181

182

183

184

185

186

187

188

189

190

191

192

193

194

195

196

197

198

199

200

201

202

203

204

205

206

207

208

209

210

which is $28 \mathrm{~s} / 18 \mathrm{~s}$ greater than 1.0. This indicated that the total concentration and quality of the prepared RNA was suitable.

\section{Library construction and sequencing}

We performed library construction and sequencing as previously described by Liu et al. ( 2014). Specifically, the library was constructed with 3 micrograms of total RNA and enriched with magnetic beads coated with oligo (dT). After adding fragment buffer, the mRNA was converted to short fragments (200-300 bp). Next, we used mRNA fragments as templates to synthesize cDNA. The double-stranded cDNA was purified with a QiaQuick PCR kit, washed with EB buffer solution, and repaired at the end, and a single adenine (A) nucleotide was added. Finally, the sequencing adapters were connected to the fragments. The fragments were purified using by agarose gel electrophoresis and amplified by PCR. We then transferred the library products to an Illumina HiSeq ${ }^{\mathrm{TM}} 2000$ for sequencing analysis. It was important to use that to base calling to convert the original image data into sequences in order to obtain clean reads before further analysis.

\section{Transcriptome analysis}

We analyzed the transcriptomes using the Illumina Hiseq ${ }^{\mathrm{TM}} 2000$ platform. The raw data was uploaded to NCBI

(https://www.ncbi.nlm.nih.gov/geo/query/acc.cgi?acc=GSE147282). Using the Illumina GA Pipeline (v1.6) software, we removed more than 10\% of unknown base and low-quality base readings from the raw sequencing data. Using TopHat2 (http://tophat.cbcb.umd.edu/) software, we aligned the filtered reads with the Cucumber (chinese long v2 Genome). Reference genome and gene database information are publicly available at the website http://cucurbitgenomics.org/ (Huang et al., 2009; Li Z et al, 2011). We performed differential expression analysis using DESseq ( version 1.18.0). Benjamini and Hochberg's methods were used to control the false discovery rate and adjust the obtained $P$ values. Genes with an adjusted $P$ value of $<0.05$ and an absolute value of $\mid \log _{2}$ fold change $\geqslant 1 \mid$ according to DEseq were considered differentially expressed. Gene ontology (GO) annotation was implemented by Blast2GO software, and GO association was performed via a BLASTX search of the NCBI NR database. We conducted the GO enrichment analysis of DEGs using the BiNGO plugin.

Over represented GO terms were recognized using a hypergeometric test following Benjamini-Hochberg false discovery rate (FDR) correction with a significance threshold of 0.05. 
211 We used the KOBAS (2.0) software to carry out the KEGG enrichment analysis of theDEGs

212 (Mao et al., 2005). A $p$ value $\leqslant 0.05$ was used as the threshold to judge significantly enriched

213 DEG pathways.

\section{Verifying RNA-seq data using quantitative real-time PCR (qRT-PCR)}

215 To test the reliability of RNA-seq, we selected nine up-regulated genes for qRT-PCR. The total 216 RNA of the RNA-seq samples were treated with DNase I enzyme, and were then transformed 217 into single-strand cDNA using the GoScriptTM Reverse

218 Transcription System (Promega, Madison, WI, USA) according to the manufacturer's protocol. 219 According to its cDNA sequence, Primer 5.0 was used to design specific gene primers (Table 220 S1). Actin was used as an internal control to normalize minor differences in the number of 221 templates. qRT-PCR was performed with GoTaq qPCR Master Mix (Promega, Madison, WI, 222 USA) in a Bio-Rad iQ1 real-time PCR system (Bio-Rad, Hercules, CA, USA), The reaction 223 conditions were as follows: pre-denaturation at $95{ }^{\circ} \mathrm{C}$ for $10 \mathrm{~min}$, followed by denaturation at 95 $224{ }^{\circ} \mathrm{C}$ for $15 \mathrm{~s}$, and renaturation at $55^{\circ} \mathrm{C}$ for $1 \mathrm{~min}$ for a total of 40 cycles; and at the end of the reaction, the system was kept at $95{ }^{\circ} \mathrm{C}$ for $15 \mathrm{~s}$, followed by $60{ }^{\circ} \mathrm{C}$ for $1 \mathrm{~min}$, and finally at last at $95{ }^{\circ} \mathrm{C}$ for $15 \mathrm{~s}$. There were three biological replicates of each gene at each time point, qPCR experimental samples were the same as the RNA sequencing samples. The expression ratio was calculated using the $2^{-\Delta \Delta \mathrm{CT}}$ method.

Results

230

\section{Morphological and cytological characterization of in vitro-induced embryogenesis in cucumber}

We conducted a negative and positive contrast of the cucumber ovary culture. After 2 days of culture, some ovules were clearly enlarged, the embryo sac was also significantly enlarged (Fig. $2 \mathrm{a}$ and $\mathrm{c}$ ), but some ovules did not respond (Fig. 2a and b). After 10 days of culture, the nonembryogenic ovaries were presumed dead. In our study, we used the cells that underwent embryogenesis for sequencing analysis.(Fig. 2d).

We observed the early embryogenesis stage, embryo morphogenesis stage, and the shoot formation stage in order to determine the cytological changes that occur during embryogenesis in cucumber ovary culture. Ovaries were collected $6 \mathrm{~h}$ before anthesis and were pretreated at 4 ${ }^{\circ} \mathrm{C}$. The ovaries were then sterilized, sliced, inoculated into the medium, incubated for $2 \mathrm{~d}$ at 33 
241

242

243

244

245

246

247

248

249

250

251

252

253

254

255

256

257

258

259

260

261

262

263

264

265

266

267

268

269

270

271

272

${ }^{\circ} \mathrm{C}$ in the dark, and then transferred to $25^{\circ} \mathrm{C}$ conditions until plants formed. Notably, our morphological and cytological observations showed that critical developmental transitions in the embryos occurred at $2 \mathrm{~d}$ (T1), $10 \mathrm{~d}$ (T2), $20 \mathrm{~d}$ (T3), $30 \mathrm{~d}$ (T4) and $60 \mathrm{~d}$ (T5) of culture. Fresh unpollinated ovaries before culture were referred to as T0 (Fig. 3). At T0, we selected the fresh unpollinated ovaries with clear ovules (Fig. 3a) and mature embryo sacs (Fig. 3g). At T1, heat shock stress induced the embryogenesis of cucumber. The most obvious indicators of embryo development were enlarged cells in the embryo sac (Fig. $3 b$ and h). Enlarged microspores have shown a correlation with embryogenic potential acquisition during androgenesis induction in many crop species (Hoekstra et al., 1996; Maraschin, 2005). After culturing for $2 \mathrm{~d}, 4 \mathrm{~d}$, and $6 \mathrm{~d}$, the expanded cells formed two (Fig. 3i), four (Fig. 3j), and multiple cell structures (Fig. 3k), respectively. At T2 $(10 \mathrm{~d})$, the ovules had successfully protruded from the surrounding tissues and a pro-embryo had formed (Fig. 3c). At T3 (20 d), the total number of embryos had increased in one ovary slice (Fig. 3d). From T3 to T4 (30 d culture), the whole embryo had formed with globular, heart-shaped, torpedo-shaped, and cotyledon-shaped (Fig. 31). At the same time, the color of the embryonic cells appeared green, indicating the beginning of plant development from the embryo (Fig. 1e). At T5 (60 d after culture), shoots had formed (Fig. 3f).

At T1, ovule enlargement and cell enlargement were clearly observed, suggesting that the transformation of the developmental pathway from the gametophyte to the sporophyte was induced by stress, and that the stage between T0 and T1 was the key to inducing embryogenesis. After the switch in cell development, embryogenic potential was acquired. Mitosis then occurred to continuously form pro-embryos, globular embryos, heart-shaped embryos, torpedo-shaped embryos, and cotyledon-shaped embryos, similar to those observed during zygote development, and this process continued until T4. After $60 \mathrm{~d}$ of culture, the cotyledon-shaped embryos developed into shoots. We divided the six culture time points into three stages: T0 to T1 (early embryogenesis stage), T1 to T4 (embryo morphogenesis stage), and T4 to T5 (shoot formation stage).

\section{Sequencing and aligning to the reference genome}

Based on our observation of the morphological and cytological characteristics, we selected six time points and used three biological replicates for RNAseq, and ultimately represented a total of 18 libraries. The transcriptome data were generated using Illumina II HiSeq ${ }^{\mathrm{TM}} 2000$ sequencing. Overall, more than 101.3 billion paired-end reads passing filter were generated, and we used these to align to the reference genes, which provided the general information for the 
273 project (Table S2). Reads counts were generated from BAM alignment files using HTseq 0.6.1p2 274 software (http://www-huber.embl.de/users/anders/HTseq). Data normalization was implemented 275 with Reads Per Kilobase of transcript, per Million mapped reads (RPKM).

To analyze the ovary culture biochemical process on the cucumber transcriptome, we

277

278

279

280

281

282

283

284

285

286

287

288

289

290

291

292

293

294

295

296

297

298

299

300

301

302

303

304 conducted transcriptomic analysis of T0 vs. T1(the control group), and the experimental groups T1 vs. T2, T2 vs. T3, T3 vs. T4, and T4 vs. T5 to reveal significantly genes. We determined which genes were differentially expressed using DESeq (version 1.18.0), and used Padjust $\leq 0.05$ and the absolute value of $\mid \log _{2}$ foldchange $\mid \geq 1$ as the threshold to judge the significance of the differential gene expression. Between T0 vs. T1; T1 vs. T2; T2 vs. T3; T3 vs. T4; and T4 vs. T5 there were 3,468; 2,341; 1,117; 1,478 and 1,383 up-regulated genes, and 3,065; 1,906; 574; 2,223 and 1,837 down-regulated genes, respectively (Fig. 4).

\section{Validation of differentially expressed genes}

Validation of the Illumina sequencing data and the DEG expression patterns revealed by RNAseq was performed in order to examine the expression patterns of nine DEGs: including seven genes involved in plant hormone signal transduction and two plant-pathogen interaction genes. qRT-PCR results showed that seven genes were involved in plant hormone signal transduction, Csa7M452370.1, Csa1M006300.1, Csa5M223020.1, Csa5M434550.1, Csa5M623800.1, Csa6M383530.1, and Csa3M389850.1, with Pearson's r $=0.77,0.57,0.74,0.79,0.69,0.81$, and 0.86 , respectively. The two genes involved in plant-pathogen interaction, Csa7M420160.1 and Csa1M006320.1, had Pearson's r values of 0.62 and 0.81 , respectively. The results showed a correlation between the relative expression levels revealed by RNA-seq and qRT-PCR. The fold changes in the qRT-PCR analysis were different from those in the RNA-seq analysis, which may have been due to the different sensitivities between the qRT-PCR analysis and the RNA-seq technique. However, the qRT-PCR analysis showed that the up-regulation and down-regulation trends of the differential gene expression were consistent with those of the RNA-seq analysis (Fig. 5).

\section{Embryogenesis-related genes expression in cucumber ovary culture}

Ovule enlargement was noticeable at the early stage of embryogenesis, following heat shock stress (Fig. 3b). Cytological observations also showed that one of the cells in the embryo sac expanded (Fig. 3h), suggesting acquisition of embryogenic potential.

We determined that the differentially expressed genes at this stage (T0 vs. T1) were comprised of 3,468 up-regulated genes and 3,065 down-regulated genes (Fig. 4). We performed a GO 
305

306

307

308

309

310

311

312

313

314

315

316

317

318

319

320

\section{1}

322

323

324

325

326

327

328

329

330

331

332

333

334

335

336

enrichment analysis of these genes, and the results showed that the proteins encoded by these genes were assigned to four biological processes, three molecular functions, and nine cellular components (Table S3). The majority of DEGs were involved in the 'single-organism process' (GO:0044699) and the 'oxidation-reduction process' (GO:0055114). They were mainly distributed across the terms 'membrane' (GO:0016020), 'membrane part' (GO:0044425), 'intrinsic component of membrane' (GO:0031224), and 'integral component of membrane' (GO:0016021), with good molecular oxidoreductase activity (GO:0016491). Among the DEGs, the expression of related genes involved in functional classification might play an important role in early embryogenesis.

To compare and summarize the results of this stage, we performed a pathway analysis to identify potential target genes. Based on the KEGG database, the pathway enrichment analysis of these genes revealed significant involvement in eight distinct pathways (Fig. 6a): pathways involving plant hormone signal transduction, phenylpropanoid biosynthesis, plant-pathogen interaction, glutathione metabolism, cysteine and methionine metabolism, drug metabolismcytochrome P450, phenylalanine metabolism, and metabolism of xenobiotics by cytochrome P450.

\section{Plant hormone signal transduction genes}

The DEGs were significantly enriched in the plant hormone signal transduction pathway (Ko04075), We detected a large number of genes related to cytokinin and ethylene signalling pathways, histidine phosphotransferase protein encoders (Csa2M373410.1, Csa6M067360.1, and Csa7M452370.1), response regulators (RR) (Csa1M006300.1, Csa3M822100.1, Csa4M436980.1, Csa5M223020.1, Csa5M434550.1, Csa5M603910.1, Csa5M623800.1, and Csa6M383530.1), EIN3 binding (F-box) proteins (EBFs) (CsaUNG009930), and ethylene-responsive protein transcription factors (ERFs) (Csa3M389850.1) that were significantly up-regulated after heat treatment (Table S4). Moreover, the partially up-regulated DEGs encoding auxin influx carriers, auxin-responsive proteins, SAUR family proteins, abscisic acid receptor proteins, serine/threonine-protein kinases, ABA-responsive element binding factors, and brassinosteroid signal-responsive protein kinases were significantly enriched in eight pathways, some of which involved tryptophan metabolism as well as zeatin, carotene, and brassinosteroid biosynthesis, suggesting that hormone production and signal transduction were closely related to stressinduced embryogenesis. The up-regulated genes encoding major enzymes and the receptor proteins involved in the plant hormone signal transduction pathway were expressed during the 
337 whole ovary culture stage . Most of the genes were dynamically expressed after their up338 regulated expression during embryogenesis. Six genes (Csa6M125240.1, Csa6M147590.1, 339 Csa6M007440.1, Csa4M454150.1, CsaUNG009930, and Csa3M389850.1) were up-regulated 340 only at the embryo initiation stage, and then appeared down-regulated in the later stages (Fig. 7).

341 These genes mainly encoded auxin synthetase and induced proteins, ABA protein kinase, and 342 ethylene-responsive transcription factors, indicating that they might be closely related to 343 embryogenesis.

344 Stress response proteins related to plant defense mechanisms

345 DEGs were significantly enriched in the plant-pathogen interaction pathway, which is related to 346 plant defense mechanisms and complex physiological responses to heat shock-induced 347 embryogenesis. In this regulatory pathway, the expression of Pto-interacting protein 1 (Ptil, 348 Csa7M420160.1), Heat shock protein 90 (HSP90, Csa3M183950.1), Enhanced disease 349 susceptibility 1 (EDS1, Csa1M006320.1), and other related genes were up-regulated (Table S4). 350 HSP90 was up-regulated under heat stress, had been highly conserved during evolution and has 351 plant defense functions.

\section{Embryogenesis-related transcription factors}

353 Transcription regulation through transcription factors is a key step in a plant's stress response. In 354 the embryogenesis stage, a total of 32 transcription factor families were up-regulated after heat 355 shock stress (Table S4). Among these, the AP2/ERF, WRKY, basic helix loop helix (bHLH), $356 M Y B, G A T A$, heat stress factor (HSF) and NAM/ATAF/CUC (NAC) families had the most 357 transcription factors. There were 26 transcription factors up-regulated in the AP2/ERF family, 358 which plays an important role in ethylene response, brassinolide response, and biological and abiotic stress responses. Two BBM genes (Csa3M827310.1 and Csa3M827320.1) were upregulated. Nineteen transcription factors were up-regulated in the $W R K Y$ family, which are involved in physiological embryo development, metabolism, environmental stress, and defense response to pathogens. The $b H L H$ family plays an active role in regulating environmental stress. The $M Y B$ family controls different stages of cell division and promoting embryogenesis. After heat shock stress, four HSF genes (Csa2M356690.1, Csa6M517310.1, Csa1M629180.1, and Csa3M822450.1) were specifically expressed that could activate the HSP90 gene in response to embryogenesis and the active regulation of biological and abiotic stress processes. 
369 In the embryo morphogenesis stage, the gametophyte development pathway switched to the 370 sporophyte development pathway, and the cells enlarged initiated mitosis, and formed two-cell,

371

372

373

374

375

376

377

378

379

380

381

382

383

384

385

386

387

388

389

390

391

392

393

394

395

396

397

398

399

400

four-cell, and multicellular pro-embryos after heat stress (Fig. 3h-k). Afterward, globular embryos, heart-shaped embryos, torpedo-shaped embryos, and cotyledon embryos were formed (Fig. 31). The DEG analyses of T1 vs. T2. T2 vs. T3, and T3 vs. T4 revealed 480 continuously expressed genes. Additionally, the numbers of uniquely expressed genes between T1 and T2, T2 and T3, and T3 and T4 were 2,236; 371 and 1,558, respectively (Fig. 8).

The GO categories of the 480 continuously expressed genes were significantly assigned to two biological processes, cell movement or subcellular component (GO:0006928) and microtubule-based movement (GO:0007018), which are mainly associated with microtubules (GO:0005874), supramolecular fibers (GO:0099512), and polymeric cytoskeletal fibers (GO:0099513). Subsequently, the proteins encoded by these genes were classified into 11 functional categories: protein complex binding (GO:0032403), microtubule binding (GO:0008017), tetrapyrrole binding (GO:0046906), tubulin binding (GO:0015631), microtubule motor activity (GO:0003777), motor activity (GO:0003774), macromolecular complex binding (GO:0044877), heme binding (GO:0020037), oxidoreductase activity (GO:0016491), iron ion binding (GO:0005506), and oxidoreductase activity (GO:0016491), acting on paired donors or the molecular incorporation of oxygen (GO:0016705) (Table S5). These findings indicated that during certain stages, the cytoskeleton structure was continuously built and maintained by the action of microtubule binding proteins and enzyme modifications. This provided the basis for positioning the various organelles and implementation functions, in order to ensure the orderly activities of various cells in time and space.

To determine the involvement of these DEGs in embryo development, we performed a pathway analysis to identify the potential target genes. Seventeen significant pathways were obtained by mapping to the KEGG database (Fig. 6b): protein processing in the endoplasmic reticulum, phenylpropanoid biosynthesis, photosynthesis-antenna proteins, limonene and pinene degradation, meiosis-yeast, the estrogen signaling pathway, cell cycle, cell cycle-yeast, diterpenoid biosynthesis, chloroalkane and chloroalkene degradation, carotenoid biosynthesis, progesterone-mediated oocyte maturation, glycerolipid metabolism, histidine metabolism, fatty acid degradation, antigen processing and presentation, and ascorbate and aldarate metabolism. Among these, the protein processing pathways in the endoplasmic reticulum and phenylpropanoid biosynthesis were the most significant. 
401 Main oxidation-reduction and metabolic process-related genes expression in cucumber 402 ovary culture

403 In the shoot formation stage, the embryos further differentiated into shoots (Fig. 3f). A total of 3,320 genes were differentially expressed between T4, and T5, 1,383 of which genes were up-

405

406

407

408

409

410

411

412

413

414

415

416

417

418

419

420

421

422

423

424

425

426

427

428

429

430

431 regulated and 1,837 were down-regulated in T5 (Fig. 4). Next, we performed an enrichment analysis of the genes using GO, which revealed eighteen biological processes, fifteen molecular functions, and five cellular components (Table S6). The terms annotated under the biological process category mainly included oxidation-reduction processes (GO: 0055114), the regulation of primary metabolic processes (GO: 0080090), the regulation of cellular metabolic processes (GO: 0031323), and the regulation of macromolecule metabolic processes (GO: 0060255). The molecular function category mainly included the terms oxidoreductase activity (GO: 0016491) and DNA binding (GO: 0003677). The cellular component category included mainly extracellular region (GO: 0005576). Ovary culture development was mainly focused on the oxidation-reduction and metabolism processes.

The DEGs were subsequently annotated using the KEGG database in order to identify pathway enrichments. A variety of pathways were found to be significantly enriched (Fig. 6c), including those involved in phenylpropanoid biosynthesis; plant hormone signal transduction; stilbenoid, diarylheptanoid, and gingerol biosynthesis; metabolism of xenobiotics by cytochrome P450; drug metabolism-cytochrome P450; flavonoid biosynthesis; phenylalanine metabolism; starch and sucrose metabolism; and zeatin biosynthesis. Most of the DEGs were enriched in phenylpropanoid biosynthesis, plant hormone signal transduction, phenylalanine metabolism, and starch and sucrose metabolism. Pathways involving phenylpropanoid biosynthesis and phenylalanine are important for metabolizing secondary metabolites in plants and are closely related to cell differentiation and pigmentation in plant development. In the plant hormone signal transduction pathway, the expression of an auxin response factor, the gibberellin receptor GID1, ethylene-responsive transcription factor $1(E R F 1)$ and cyclin D3 were up-regulated, showing that they promoted plant development, morphogenesis, cell enlargement, division and stem developmen. Additionally, the DEGs involved in starch and sugar metabolism were also significantly enriched and mainly encoded 3- $\beta \mathrm{D}$ glucosidase, T6Ps, GlgB, endoglucanase, and alpha-trehalase, which satisfied the requirements of embryo growth and development.

\section{Shoot formation-related transcription factors}


432 In the shoot formation stage, the 62 transcription factors that were up-regulated belonged to 23

433 transcription factor families, with an up-regulation ratio between 2.03 and 214.13. The most up-

434 regulated gene was the TCACG motif-binding factor (TGA) transcription factor

435 (CSA4M625020.1) in the basic leucine zipper (bZIP) family. It which can specifically bind to

436 the activation sequence with $T G A C G$ as the core in order to regulate the transcription level of

437 target genes, and it plays an important role in organ development and the defense response

438 against biological and abiotic stress. AP2/EFR, bHLH, MYB, WRKY, ZIP and WUSCHEL-related

439 homeobox $(W O X)$ are the families with a large number of transcription factors, which may be an

440 important molecular indicator of shoot formation.

\section{Discussion}

442 In this present study, the whole process from acquisition of embryogenic potential to plant 443 regeneration was investigated. We divided the ovary culture into three stages. In the early stage 444 of embryogenesis, the acquisition of embryogenic potential by stress (e.g., low or high 445 temperature or hormone induction) was observed together with the repression of gametophytic 446 development, leading to cell dedifferentiation. In the embryo morphogenesis stage, cell divisions 447 gave rise to the formation of pro-embryos (cell clumps), globular embryos, heart-shaped 448 embryos, torpedo-shaped embryos, and cotyledon embryos. In the shoot formation stage, 449 cotyledon embryos developed into shoots. There were molecular events that regulated embryo 450 development at different stages of development.

\section{Embryogenesis-related genes are expressed in cucumber ovary culture}

452 In the early stage of embryogenesis, the female gametophyte was regulated by a variety of

453 hormones, including auxin, abscisic acid, cytokinin and ethylene, similar to somatic cell

454 embryogenesis and transformation (Ikeda-Iwai et al., 2003). A large number of DEGs were

455 enriched in the plant hormone signal transduction pathway. Phytohormones such as cytokinin

456 and ethylene were significantly up-regulated in multiple biosynthesis and metabolic pathways,

457 and up-regulated and down-regulated genes related to auxin and abscisic acid were both

458 observed. Generally, high-level endogenous cytokinin and low-level endogenous ethylene are

459 beneficial for the acquisition of embryogenic ability. Embryogenesis is the comprehensive

460 performance of interactions across different hormones, and all kinds of endogenous hormones

461 show dynamic changes. The up-regulated expression of the main enzymes and receptor proteins 
462 in the plant hormone signal transduction pathway could promote embryogenesis, indicating that 463 the high expression levels of related genes may play important roles in the process of switching 464 from the gametophyte to the sporophyte development pathway. In this pathway, we found six

465

466

467

468

469

470

471

472

473

474

475

476

477

478

479

480

481

482

483

484

485

486

487

488

489

490

491

492

493

genes related to hormone regulation (Csa6M125240.1, Csa6M147590.1, Csa6M007440.1,

Csa4M454150.1, CsaUNG009930, and Csa3M389850.1) that were highly expressed only at the embryo initiation stage, then were down-regulated in the later stages. Additionally, we determined the functional categories and regulatory pathways of the specific functions that lay an important theoretical foundation for understanding this mechanism.

In in vitro culture, a certain stress condition is needed to block the development direction of the original gametophyte, which needs to be turned towards the direction of the sporophyte, and continue symmetry splitting in order to eventually lead to embryogenesis (Fan et al.,1988). In cucumber ovary culture, heat shock pre-treatment, silver nitrate, genotype and hormone combination factors can independently and simultaneously play key roles in embryo and callus production (Golabadi et al., 2017). In this study, heat shock stress was an important factor in the transformation from gametophyte to sporophyte. Previous studies have shown that HSP genes are specifically expressed in the spore stress-induction process of many crop species (Zarsky et al., 2010; Binarova et al., 1997; Sabehat et al., 1998). HSP genes play important roles in cell cycle control, genomic silencing, protein transduction and signal transduction (Zhang et al, 2013). We found that 26 up-regulated genes encoded proteins and transcription factors related to heat shock, and that HSP90 (Csa3M183950.1) was involved in the regulation of the hypersensitive response in the plant and pathogen interaction pathway. The expression of these genes might play a regulatory role in the embryogenesis process. The $B B M$ gene is preferentially expressed in developing embryos and seeds (Boutilier et al., 2002), and is a key regulator of plant cell totipotency because $B B M$ ectopic overexpression induces the formation of somatic embryos in Arabidopsis seedlings without exogenous growth regulators or stress treatments (Boutilier et al.,2017). We found that two BBM genes (Csa3M827310.1 and Csa3M827320.1) were upregulated at the beginning of embryogenesis and were subsequently down-regulated. Additionally, $A G L 15$, a member of the MADS family, is also considered a regulatory protein that acts at the start of cell division (Perry et al., 1999). We found that the $A G L$ gene (Csa3M258140.1) was up-regulated in our study, indicating that all three of these genes (BBM, HSP90 and $A G L$ ) play important roles in the induction of embryogenesis by cucumber ovary culture.

Peer] reviewing PDF | (2019:12:44356:4:1:NEW 28 Jul 2021) 
494

495

496

497

498

499

500

501

502

503

504

505

506

507

508

509

510

511

512

513

514

515

516

517

518

519

520

521

522

523

524

525

Gametophyte embryogenesis and zygotic embryogenesis are similar processes, and the only difference is that the former occurs in sex cells while the latter occurs in fertilized egg cells during the development and differentiation of zygotic embryos. Microtubules play an important role in cells between the polarized diffuse growth and the acquisition stages (Kimata, et al., 2016). Electron microscope-based observations of carrot culture showed that the appearance of microtubules was accompanied by the formation of somatic embryos (Halperin et al., 1967). The different patterns of microtubule organization in the cells of the mature embryo sac cells reflect their structural adaptations for their future function (Huang et al., 1994). Similar to somatic embryos, a large number of genes participated in microtubule movement and bind to tubulin after embryonic potential is acquired, and the different embryo shapes form through active cell metabolism and rapid cell division. We concluded that the cellular reprogramming and morphological changes in embryos were controlled by microtubule organization genes.

Cotyledon embryos are further cultured to form shoots, and at this stage, a large number of transcription factors were expressed. The first constitutes transcription factors that contain a B3 domain (Stone et al., 2001). These transcription factors encode regulatory proteins involved in the embryonic development process, and maintaining embryo development during late embryonic development (Boutilier et al., 2002; Riechmann \& Meyerowitz, 1998). In our study, a total of six transcription factors (Csa2M359980.1, Csa2M292240.1, Csa5M608380.1, Csa6M489980.1, Csa6M489940.1, and CsaUNG031640) containing a B3 domain were upregulated. The second was the AIL gene from the AP2/ERF family, which is involved in key developmental processes throughout the whole plant life cycle. Some genes in the AP2/ERF gene family are expressed in many other tissues and participate in many plant developmental processes, such as embryogenesis and shoot development (Boutilier et al., 2002; Riechmann \& Meyerowitz, 1998). Additionally, we found that the expression levels of nine genes (Csa1M423190.1, Csa3M114480.1, Csa3M652380.1, Csa3M114470.1, Csa4M644740.1, Csa5M175970.1, Csa5M608380.1, Csa6M496390.1, and CsaUNG031640) from the AP2/ERF family were up-regulated. Furthermore, WUS homologous domain proteins not only alter the cell fate of the shoot and flower meristem, but they also promote the development of somatic embryos into seedlings. WUS proteins have no direct connection to the embryo characteristics, but they will alter the development state of the tissue by maintaining cells in an un-differentiated state in response to different stimuli (Mayer et al., 1998; Gallois et al., 2004). WUS's ability to transform the vegetative growth phase to the embryonic stage, as well as to eventually form 
526 somatic cells, indicates that this homologous domain protein also plays an important role in

527 embryo morphogenesis and meristem (Palovaara \& Hakman, 2008). In the shoot apical meristem,

528 WUS defines the organizing center and is critical for the induction of these cells (Dai et al., 2017;

529 Meng et al., 2017). During this stage, two genes (Csa6M301060.1 and Csa6M505860.1)

530 encoding WUS homologous domain proteins were up-regulated. We concluded that those

531 homologous domain proteins might directly or indirectly regulate shoot formation.

532 Because the ovary culture embryogenesis takes place in the surrounding tissue, it was 533 difficult to observe the embryo development process and the transcriptome analysis sample was 534 difficult to select. Additionally, this study sample contained other tissues, especially at the T0/T1 535 time points, and isolated ovules yielded sequencing materials that may have impacted the 536 transcriptome data.

\section{Conclusion}

Our study revealed the molecular events of embryogenesis in cucumber ovary culture. The early stage of embryogenesis was the turning point for embryos formation, and a large number of hormone-related genes (Csa6M125240.1, Csa6M147590.1, Csa6M007440.1, Csa4M454150.1, CsaUNG009930, Csa3M389850.1., and BBM, HSP90 and AGL) were expressed at the stage of early embryo development. In the stage of embryo morphogenesis stage, GO analysis showed that continuously expressed genes participated in microtubule-based movement, movement of the cell, or subcellular component processes, indicating functional protein complex binding, microtubule binding, tetrapyrrole binding, tubulin binding and other microtubule activity, which are involved in protein processing in the endoplasmic reticulum and phenylpropanoid biosynthesis. Shoot formation was regulated by six transcription factors that contained a B3 domain, a total of nine genes in the AP2/ERF family, and two genes that encoded WUS homologous domain proteins. This evaluation of molecular events in gynogenesis may be useful for understanding the molecular mechanism of cucumber ovarian culture. 
552

553

554

555

556

557

558

559

560

561

562

563

564

565

566

567

568

569

570

571

572

573

574

575

576

577

578

\section{REFERENCES}

Bélanger S, Marchand S, Jacques PÉ, Meyers B, Belzile F. 2018. Differential expression profiling of microspores during the early stages of isolated microspore culture using the responsive barley cultivar gobernadora. Genes Genomes Genetics 8:1603-1614.

Binarova P, Hause G, Cenklová V, Cordewener JHG, Looderen Campagne MM. 1997. A short severe heat shock is required to induce embryogenesis in late bicellular pollen of Brassica napus L.. Sexual Plant Reproduction 10:200-208.

Boutilier K, Offringa R, Sharma VK, Kieft H, Ouellet T, Zhang L, Hattori J, Liu CM, van Lammeren AAM, Miki BLA, Custers JBM, van Looleren Campagne MM. 2002. Ectopic expression of $B A B Y B O O M$ triggers a conversion from vegetative to embryonic growth. Plant Cell 14:1737-1749.

Chen JF, Cui L, Malik AA, Kere George Mbira. 2011. In vitro haploid and dihaploid production via unfertilized ovule culture. Plant Cell Tissue and Organ Culture 104:311-319.

Dai XH, Liu ZH, Qiao M, Li J, Li S, Xiang FN. 2017. ARR12 promotes de novo shoot regeneration in Arabidopsis thaliana via activation of WUSCHEL expression. Journal of Integrative Plant Biology 59: 747-758.

Deng Y, Tang B, Zhou X, Fu WY, Tao L, Zhang L, Chen JF. 2020. Direct regeneration of haploid or doubled haploid plantlets in cucumber (Cucumis sativus L.) through ovary culture. Plant Cell Tiss Organ Cult. https://doi.org/10.1007/s11240-020-01839-w.

Diao WP, Jia YY, Song H, Zhang XQ, Lou QF, Chen JF. 2009. Efficient embryo induction in cucumber ovary culture and homozygous identification of the regenetants using SSR markers. Scientia Horticulturae 119:246-251.

Fan Z, Armstrong KC, Keller WA. 1988. Development of microspores in vivo, and in vitro, in Brassica napus L. Protoplasma 147:191-199.

Gallois J-L, Nora FR, Mizukami Y, Sablowski R. 2004. WUSCHEL induces shoot stem cell activity and developmental plasticity in the root meristem. Genes \& Development $18(4): 375-380$. 
579

580

581

582

583

584

585

586

587

588

589

590

591

592

593

594

595

596

597

598

599

600

601

602

603

604

605

Gémes-Juhász A, Balogh P, Ferenczy AZ, Kristóf. 2002. Effect of optimal stage of female gametophyte and heat treatment on in vitro gynogenesis induction in cucumber (Cucumis sativus L.). Plant Cell Reports 21:105-111.

Golabadi M, Ghanbari Y, Ghanbari S, Keighobadi K. 2017. Embryo and callus induction by different factors in ovary culture of cucumber. Journal of Applied Botany \& Food Quality 90:68-75.

Golabadi M, Golkar P, Eghtedary AR. 2012. Assessment of genetic variation in cucumber (Cucumis sativus L.) genotypes. European Journal of Experimental Biology 2 :1382-1388.

Guha S, Maheshwari SC. 1964. In vitro production of embryos from anthers of datura. Nature 204:497.

Halperin W, Jensen WA. 1967. Ultrastructural changes during growth and embryogenesis in carrot cell cultures. Journal of Ultrastruct Research 18:428-443.

Hoekstra S, Hoekstra IR, Hoekstra RA, Hoekstra E. 1996. The Interaction of 2, 4-D application and mannitol pretreatment in anther and microspore culture of Hordeum vulgare L. cv. Igri. Journal of Plant Physiology 148:696-700.

Hosp J, Tashpulatov A, Roessner U, Barsova E, Katholnigg H, Steinborn R, Melikant B, Lukyanov S, Heberle-Bors E, Touraev A. 2007. Transcriptional and metabolic profiles of stress-induced, embryogenic tobacco microspores. Plant Molecular Biology 63:137-149.

Huang BQ, Sheridan WF. 1994. Female Gametophyte Development in maize: microtubular organization and embryo sac polarity. Plant Cell 6:845-861.

Huang SW, Li RQ, Zhang ZH, Li L, Gu XF, FanW, William J L, Wang XW, Xie BY, Ni PX, Ren YY, Zhu HM, Li J, Lin K, Jin WW, Fei ZJ, Li GC, Jack Staub, Andrzej Kilian, Edwin A G van der Vossen, Wu Y, Guo J, He J, Jia ZQ, Ren Y, Tian G, Lu Y, Ruan J , Qian WB, Wang MW, Huang QF, Li B, Xuan ZL, Cao JJ, Asan, Wu ZG, Zhang JB, Cai QL, Bai YQ, Zhao BW, Han YH, Li Y, Li XF, Wang SH, Shi QX, Liu SQ, Won Kyong Cho, Jae-Yean Kim, Xu Y, Katarzyna Heller-Uszynska, Miao H, Cheng ZC, Zhang SP, Wu J, Yang YH, Kang HX, Li M, Liang HQ, Ren XL, Shi ZB, 
606

607

608

609

610

611

612

613

614

615

616

617

618

619

620

621

622

623

624

625

626

627

628

629

630

631

632

633

Wen M, Jian M, Yang HL, Zhang GJ, Yang ZT, Chen R, Liu SF, Li JW, Ma LJ, Liu H, Zhou Y, Zhao J, Fang X, Li GQ, Fang L, Li YR, Liu DY, Zheng HK, Zhang Y, Qin N, Li Z, Yang GH ,Yang S, Lars Bolund, Karsten Kristiansen, Zheng HC, Li SC, Zhang XQ, Yang HM, Wang J, Sun RF, Zhang BX, Jiang SZ, Wang J, Du YC and Li SG. 2009. The genome of the cucumber, Cucumis sativus L. Nat. Genet. 41, 1275-1281.

Ikeda-Iwai M, Umehara M, Satoh S, Kamada H. 2003. Stress- induced somatic embryogenesis in vegetative tissues of Arabidopsis thaliana. Plant Journal 34:107-114.

Irikova T, Grozeva S, Denev I. 2012. Identification of BABY BOOM and LEAFY COTYLEDON genes in sweet pepper (Capsicum annuum L.) genome by their partial gene sequences. Plant Growth Regulation 67:191-198.

Kimata Y, Higaki T, Kawashima T, Kurihara D, Sato Y, Yamada T, Hasezawa S, Berger F, Higashiyama T, Ueda M. 2016. Cytoskeleton dynamics control the first asymmetric cell division in Arabidopsis zygote. Proc Natl Acad Sci USA 113(49):14157-14162. doi:10.1073/pnas.1613979113.

Li J, Wu Z, Cui L, Zhang TL, Guo QW, Xu J, Jia L, Lou QF, Huang SW, Li ZG, Chen JF. 2014. Transcriptome comparison of global distinctive features between pollination and parthenocarpic fruit set reveals transcriptional phytohormone cross-talk in cucumber (Cucumis sativus L.). Plant \& Cell Physiology 55(7):1325-1342.

Li JW, Si SW, Cheng JY, Li JX, Liu JQ. 2013. Thidiazuron and silver nitrate enhanced gynogenesis of unfertilized ovule cultures of Cucumis sativus. Biologia Plantarum 57:164168.

Liu C, Liu ZY, Ye XL, Wang YH, Meng Q and Feng H. 2014. Transcriptome Analysis of the Chinese Cabbage (Brassica rapa Ssp. Pekinensis) Petal Using RNA-Seq. Journal of Horticulture 1: 114. doi: 10.4172/2376-0354.1000114.

Lv J , Qi J , Shi Q, Shen D, Zhang S, Shao G, Li H, Sun ZY, Weng Y, Gu XF, Li XX, Zhu XG, Zhang JZ, van Treuren R, van Dooijeweert W, Zhang ZH, Huang S. 2012. Genetic diversity and population structure of cucumber (Cucumis sativus L.). PLoS ONE 7:e46919.

PeerJ reviewing PDF | (2019:12:44356:4:1:NEW 28 Jul 2021) 
634

635

636

637

638

639

640

641

642

643

644

645

646

647

648

649

650

651

652

653

654

655

656

657

658

659

660

Li Z, Zhang Z, Yan P, Huang S, Lin K. 2011. RNA-Seq improves annotation of proteincoding genes in the cucumber genome. BMC Genomics 12:540

Malik MR, Wang F, Dirpaul JM, Zhou N, Polowick PL, Ferrie, AMR, Krochko JE. 2007. Transcript profiling and identification of molecular markers for early microspore embryogenesis in Brassica napus. Plant Physiology 144:134-154.

Mao X, Cai T, Olyarchuk JG, Wei L. 2005. Automated genome annotation and pathway identification using the KEGG Orthology $(\mathrm{KO})$ as a controlled vocabulary. Bioinformatics 21:3787-3793.

Maraschin SF. 2005. Androgenic switch: an example of plant embryogenesis from the male gametophyte perspective. Journal of Experimental Botany 56:1711-1726.

Mayer KF, Schoof H, Haecker A, Lenhard M, Laux T. 1998. Role of $W U S C H E L$ in Regulating Stem Cell Fate in the Arabidopsis Shoot Meristem. Cell 95:805-815.

Meng WJ, Cheng ZJ , Sang YL, Zhang MM, Rong XF, Wang ZW, Tang YY, Zhang XS. 2017. Type-B ARABIDOPSIS RESPONSE REGULATORs Specify the Shoot StEM Cell Niche by Dual Regulation of WUSCHEL. Plant Cell. The Plant cell, 29(6):13571372.doi:10.1105/ tpc.16.00640.

Metwally EI , Moustafa SA, El-Sawy BI, Haroun SA, Shalaby TA. 1998. Production of haploid plants from in vitro culture of unpollinated ovules of Cucurbita pepo. Plant Cell Tissue and Organ Culture 52:117-121.

Mól R, Filek M, Machackova I, Matthys-Rochon E. 2004. Ethylene synthesis and auxin augmentation in pistil tissues are important for egg cell differentiation after pollination in maize. Plant \& Cell Physiology 45:1396-1405.

Palovaara J, Hakman I. 2008. Conifer WOX-related homeodomain transcription factors, developmental consideration and expression dynamic of WOX2 during Picea abies somatic embryogenesis. Plant Molecular Biology 66:533-549.

Pazuki A, Aflaki F, Gürel S, Ergül A, Gürel E.2018. Production of doubled haploids in sugar 
661

662

663

664

665

666

667

668

669

670

671

672

673

674

675

676

677

678

679

680

681

682

683

684

685

686

687

688

beet (Beta vulgaris ) an efficient method by a multivariate experiment. Plant Cell Tissue Organ Culture 132:85-97. https://dio.org/10.1007/s11240-017-1313-5

Pechan PM, Bartels D, Brown DC, Schell J. 1991. Messenger-RNA and protein changes associated with induction of Brassica, microspore embryogenesis. Planta 184:161-165.(删 除)

Perry SE, Fernandez DE. 1999. The MADS-domain protein AGAMOUS-like 15 accumulates in embryonic tissues with diverse origins. Plant Physiology 120:121-129.

Plapung P, Khumsukdee S, Smitamana P. 2014. Development of cucumber lines resistant to cucumber mosaic virus by ovule culture. International Journal of Agricultural Technology 733-741.

Riechmann JL, Meyerowitz EM. 1998. The AP2/EREBP family of plant transcription factors. Biological Chemistry 379:633-646.

Rosa Angélica SánchezDíaz, Ana María Castillo, María Pilar Vallés. 2013. Microspore embryogenesis in wheat: new marker genes for early, middle and late stages of embryo development. Plant Reproduction 26:287-296.

Sabehat A, Weiss D. 1998. Expression of small heat-shock proteins at low temperatures: A possible role in protecting against chilling injuries. Plant Physiology 117:651-8.

Sangster TA, Queitsch C. 2005. The $H S P 90$ chaperone complex, an emerging force in plant development and phenotypic plasticity. Current Opinion in Plant Biology 8:86-92.

Shalaby TA. 2007. Factors affecting haploid induction through in vitro gynogenesis in summer squash (Cucurbita pepo L.). Scientia Horticulturae 115:1-6.

Stone SL, Kwong LW, Yee KM, Yee KM, Pelletier J, Lepiniec L, Fischer RL. 2001. $L E A F Y$ COTYLEDON2 encodes a B3 domain transcription factor that induces embryo development. Proceedings of the National Academy of Sciences 98:11806-11811.

Tantasawat PA, Sorntip A, Poolsawat O, Chaowiset W, Pornbungkerd P. 2015. Evaluation of factors affecting embryo-like structure and callus formation in unpollinated ovary culture of cucumber(Cucumis sativus L). International Journal of Agriculture \& Biology 17:613618.

Peer) reviewing PDF | (2019:12:44356:4:1:NEW 28 Jul 2021) 
689

690

691

692

693

694

695

696

697

698

699

700

701

702

703

704

705

706

707

708

709

710

711

712

713

714

715

716

717

718

719

720

721

722

723

724

Touraev A, Vicente O, Heberle-Bors E. 1997. Initiation of microspore embryogenesis by stress. Trends in Plant Science 2:297-302.

\section{Wang X, Bao K, Reddy UK, Bai Y, Hammar SA, Jiao C, Wehner TC, Ramírez-Madera} AO, Weng Y, Grumet R, Fei Z. 2018. The USDA cucumber (Cucumis sativus L.) collection: genetic diversity, population structure, genome-wide association studies, and core collection development. Horticulture Research. 5:64-67.

Zarsky V, Garrido D, Eller N, Eller N, Tupy J, Vicente O, Schoffl F. 2010. The expression of a small heat shock gene is activated during induction of tobacco pollen embryogenesis by starvation. Plant Cell \& Environment. 18:139-147.

Zhang J , Li J , Liu B , Zhang L, Chen J, Lu M. 2013. Genome-wide analysis of the populus HSP90 gene family reveals differential expression patterns localization and heat stress responses. BMC Genomics 14:532-546.

\section{Figures}

Fig. 1. Total RNA agarose gel electrophoresis of cucumber ovary embryos $1,2,3,4,5,6 \ldots \ldots 18=\mathrm{T} 0-1, \mathrm{~T} 0-2, \mathrm{~T} 0-3, \mathrm{~T} 1-1, \mathrm{~T} 1-2, \mathrm{~T} 1-3 \ldots \ldots \mathrm{T} 5-3$.

\section{Fig. 2. Negative and positive contrast of cucumber ovary culture}

Ovule of culture $2 \mathrm{~d}$, a- $\mathrm{L}$ and $\mathbf{b}$ non-responsive ovule, $\mathbf{a}-\mathrm{R}$ and $\mathbf{c}$ Enlarged ovule; $\mathbf{d}$ Ovaries of culture 10 days. Ov Ovule, Vb Vascular bundle, Es Embryo sac, PI Placenta, In Intergument, Ie Inner epidermis. Enlarged ovule was marked with a white arrow.

\section{Fig. 3. Embryogenic process of cucumber ovary culture}

a-f and I Observation under stereoscopic microscope. a Selected fresh unpollinated ovaries (0 d, T0). b Ovules were treated with a high temperature of $33^{\circ} \mathrm{C}$ for $2 \mathrm{~d}$; c Embryos cultured for $10 \mathrm{~d}$, note the ovule enlargement and embryo initiation. d Embryos cultured for $10 \mathrm{~d}$, with an average of six embryoids in each slice of ovary; e Embryos cultured for $30 \mathrm{~d}$, embryo morphogenesis and cotyledon-embryo formation. f Cultured for $60 \mathrm{~d}$, embryo differentiation into shoot. Histological observations: the histological sections were stained with Delafield's hematoxylin. g Multicellular embryo sac before culturing, $\mathbf{h}$ One of the cells expands in the embryo sac after $2 \mathrm{~d}$ of culture, $\mathbf{i}$ Cell mitosis occurred at $4 \mathrm{~d}$ of culture. $\mathbf{j}$ Cells continued to be divided into four cells at $6 \mathrm{~d}$ of culture. $\mathbf{k}$ A cell clumps structure was visible at $8 \mathrm{~d}$ of culture. 1 A globular-embryo switched into a cotyledon shape-embryo. Ov ovule, Ow ovary wall, Es Embryo sac, Ec Egg cell, Sy synergid, PN Polar nucleus, Ig Integument, Eb Embryo, Dc Developing cells, G-e Globular embryo, H-se Heart-shaped embryo, T-se Torpedo-shaped embryo, C-se Cotyledon-shaped embryo, S Shoot. The solid white lines represent $2 \mathrm{~mm}$, and the black lines represent $200 \mu \mathrm{m}$. 
725

726

727

728

729

730

731

732

733

734

735

736

737

738

739

740

741

742

743

744

745

746

747

748

749

750

751

752

753

754

755

756

757

758

759

760

761

762

763

764
Fig. 4. The total number of up-regulated and down-regulated genes

Black-colored bars represent up-regulated genes, and gray bars represent down-regulated genes.

Fig. 5. Validation of differentially expressed genes and the correlation between RNA-seq and qRT-PCR

qRT-PCR analysis of nine up-regulated genes involved in plant hormone signal transduction and plant-pathogen interaction genes in the whole ovary culture, a Csa7M452370.1, b Csa1M006300.1, c Csa5M223020.1 d Csa5M434550.1, e Csa5M623800.1, f Csa6M383530.1, g Csa3M389850.1, h Csa7M420160.1, i Csa1M006320.1. Close correlations (Person's r= 0.77, $0.57,0.74,0.79,0.69,0.81,0.86,0.62$, and 0.81 ) were observed between relative expression levels in RNA-seq and qRT-PCR, validating the RNA-Seq methodology described here for quantitative analysis of the cucumber transcriptome. Three biological replicates of each gene at each time point, and data were shown as mean $\pm \operatorname{SE}(n=3)$.

Fig. 6. KEGG pathway enrichment analysis based on the differentially expressed genes a Early embryo development, $\mathbf{b}$ In the stage of embryo morphogenesis, $\mathbf{c}$ In shoot stage. The longitudinal coordinates are the enriched KEGG pathways, and the x-axis monitored the rich factor; The size of the dots in the graph represents the number of differentially expressed genes annotated to the mentioned pathway, and the color represents the significant $\mathrm{P}$ value of the pathway. The most significant pathways are shown in the picture.

Fig. 7. The matrix graph of up-regulated expression genes in the plant hormone signal transduction pathway across six time points

The absolute values of the relative expression of up-regulated gene expression are indicated by the depth of color. The x-axis of the matrix graph shows the six time points. The $y$-axis of the matrix graph shows the name of the up-regulated genes. The up-regulated genes were arrayed according to their hormonal signal transduction flows, which were classified into six groups: auxin, cytokinin, abscisic acid, ethylene, brassinosteroid, and salicylic acid.

Fig. 8. Venn diagram of showed differentially expressed genes in embryo morphogenesis stage

The DEG sets (T1 vs. T2, T2 vs. T3, and T3 vs. T4) described in Fig. 4 were analyzed using the Venn method. The numbers marked in the diagram indicated the number of genes significantly expressed across the three DEGs sets.

\section{Additional files}

Table S1. Primers for real-time quantitative PCR

Table S2. Statistics of RNA-Seq alignment

Table S3. GO classification of common expressed genes in the early stage of embryogenesis

Peer] reviewing PDF | (2019:12:44356:4:1:NEW 28 Jul 2021) 
765 Table S4. Main differentially expressed genes in T0 vs T1

766 Table S5. GO classification of common expressed genes in the morphogenesis stage

767 Table S6. GO classification of common expressed genes in the shoot formed stage

768 


\section{Figure 1}

Total RNA agarose gel electrophoresis of cucumber ovary embryos

$1,2,3,4,5,6 \ldots . .18=$ T0-1, T0-2, T0-3, T1-1, T1-2, T1-3.....T5-3

$\begin{array}{lllllllllllllllllll}M & 1 & 2 & 3 & 4 & 5 & 6 & 7 & 8 & 9 & 10 & 11 & 12 & 13 & 14 & 15 & 16 & 17 & 18\end{array}$ 
Figure 2

Negative and positive contrast figure of cucumber ovary culture

$\mathbf{a}, \mathbf{b}, \mathbf{c}$ Ouvle of culture $2 \mathrm{~d}$. $\mathbf{a}$ - L and $\mathbf{b}$ non-responsive ovule. $\mathbf{a}-\mathrm{R}$ and $\mathbf{c}$ Enlarged ovule. $\mathbf{d}$ Ovaries of culture 10 days. Ov Ovule. Vb Vascular bundle. Es Embryo sac. PI Placenta. In Intergument. Ie Inner epidermis. Enlarged o vule was marked with a white arrow . 

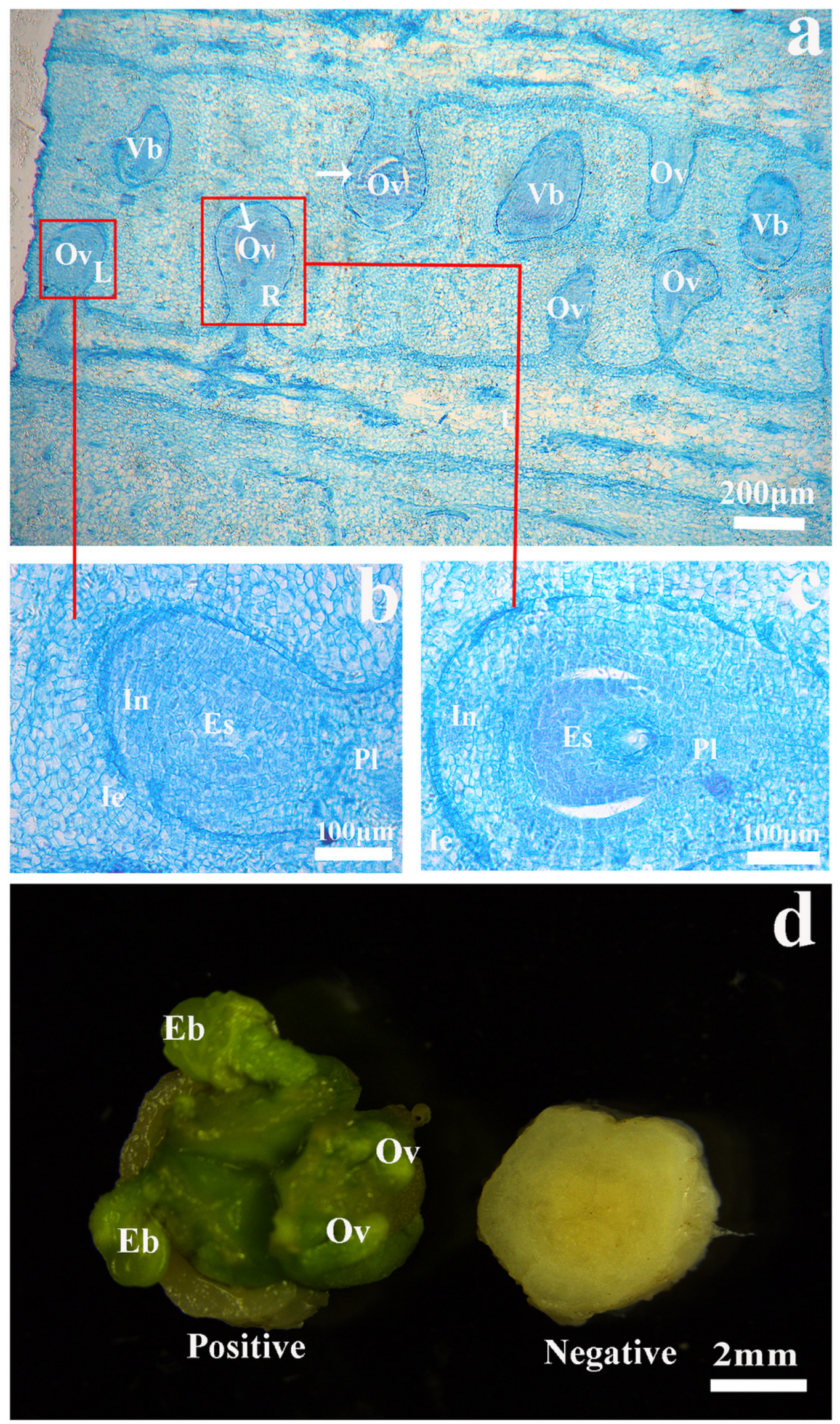


\section{Figure 3}

Embryogenic process of ovary culture in cucumber

a-f and I Observation under stereoscopic microscope. a Selected fresh unpollinated ovaries

$(0 \mathrm{~d}, \mathrm{T0})$. b Ovule were treated with the high temperature of $33^{\circ} \mathrm{C}$ for $2 \mathrm{~d}$; c Embryos

cultured for $10 \mathrm{~d}$, note the ovule enlargement and embryo initiation. $\mathbf{d}$ Embryos cultured for $10 \mathrm{~d}$, with an average of 6 embryoids in each slice of ovary; e Embryos cultured for $30 \mathrm{~d}$, embryo morphogenesis and cotyledon-embryo formation. f Cultured for $60 \mathrm{~d}$, the embryo differentiated into shoot. Histological observations: the histological sections were stained with Delafield's hematoxylin. $\mathbf{g}$ Multicellular embryo sac before culturing, $\mathbf{h}$ One of the cells expands in the embryo sac, after $2 \mathrm{~d}$ of culture, $\mathbf{i}$ Cell mitosis occurred at $4 \mathrm{~d}$ of culture. $\mathbf{j}$ Cells continue to be divided into four cells at $6 \mathbf{d}$ of culture. $\mathbf{k}$ A cell clumps structure was visible at $8 \mathrm{~d}$ of culture. I Globular-embryo switch into cotyledon shape-embryo. Ov ovule, Ow ovary wall, Es Embryo sac, Ec Egg cell, Sy synergid, PN Polar nucleus, Ig Integument, Eb Embryo, Dc Developing cells, G-e Globular embryo, H-se Heart-shaped embryo, T-se Torpedo-shaped embryo, C-se Cotyledon-shaped embryo, S Shoot. The solid white lines represent $2 \mathrm{~mm}$, and the black lines represent $200 \mu \mathrm{m}$. 


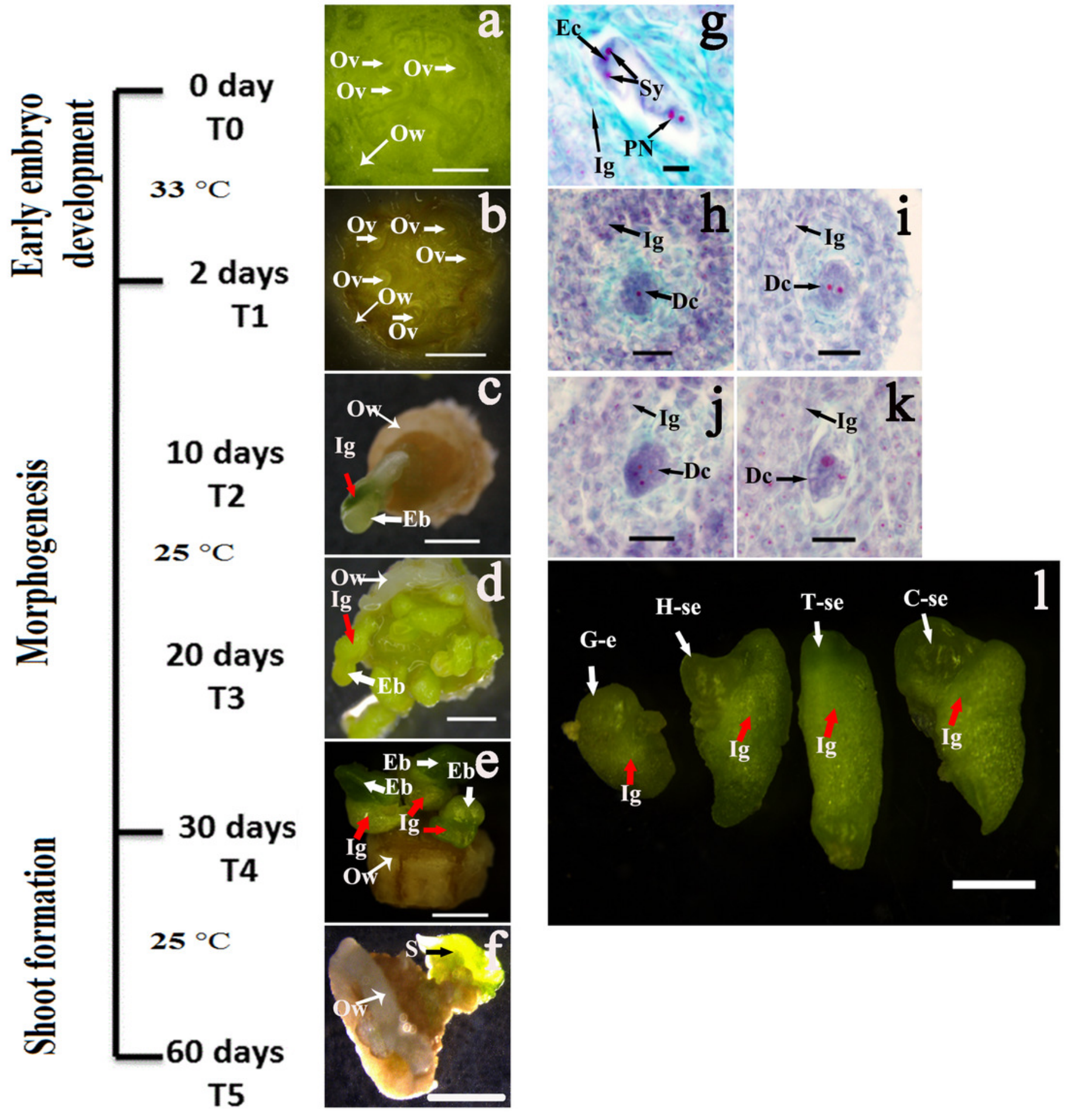


Figure 4

The total number of upregulated and downregulated genes

Black colored bars represent upregulated genes, and gray ones represent downregulated genes.

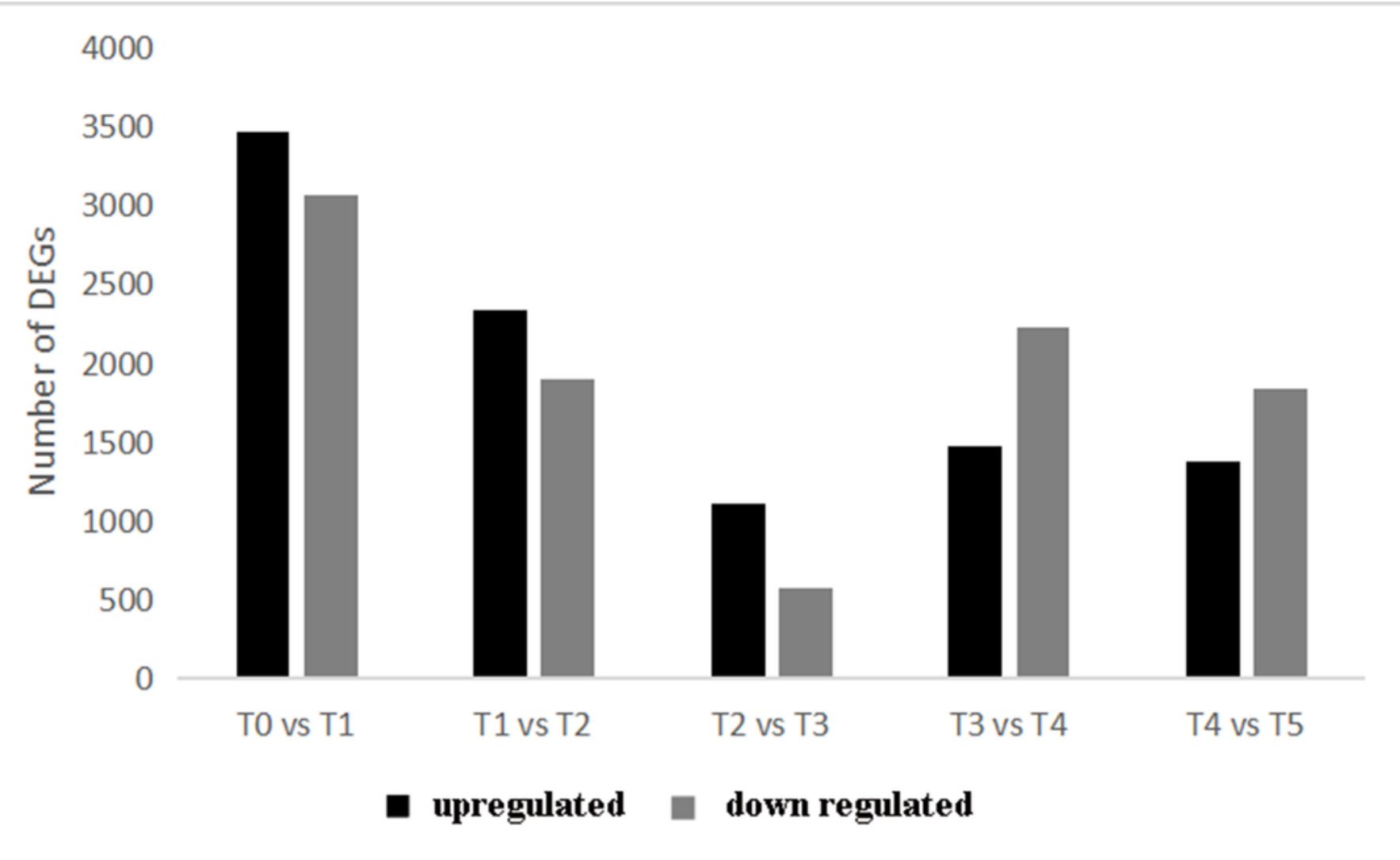




\section{Figure 5}

Validation of differentially expressed genes and correlation between RNA-seq and qRTPCR

qRT-PCR of 9 upregulated genes involved in plant hormone signal transduction and plantpathogen interaction genes in whole ovary culture were analyzed. a Csa7M452370.1 b

Csa1M006300.1, c, Csa5M223020.1 d Csa5M434550.1 , e Csa5M623800.1, f Csa6M383530.1

, g Csa3M389850.1, h Csa7M420160.1, i Csa1M006320.1. Close correlations (Person's r= $0.77,0.57,0.74,0.79,0.69,0.81,0.86,0.62,0.81$ ) were observed between relative expression levels in RNA-seq and qRT-PCR, validating the RNA-Seq methodology described here for quantitative analysis of the cucumber transcriptome. Three biological replicates of each gene at each time point, , and data were showed as mean \pm SE $(n=3)$.
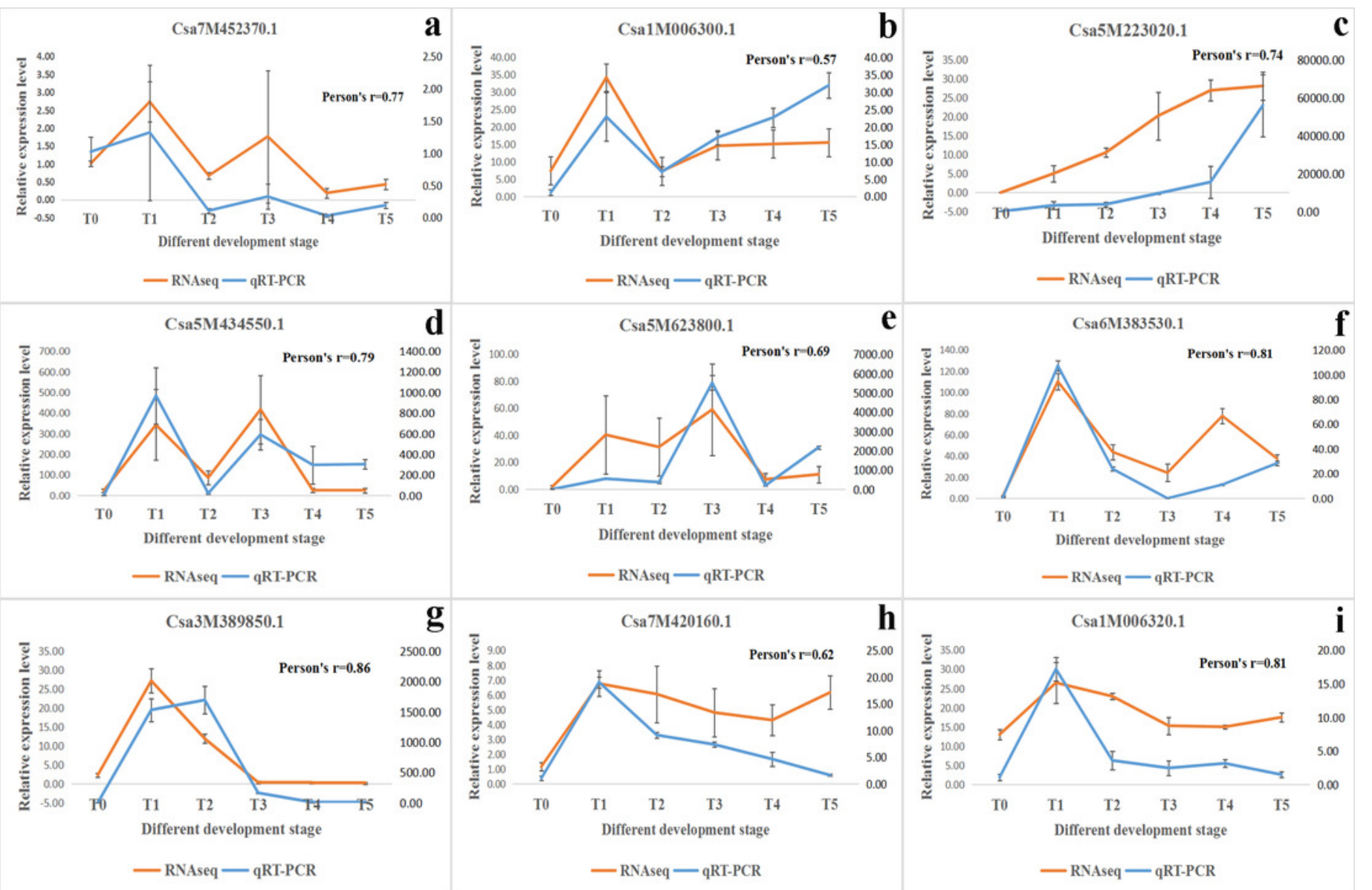
Figure 6

KEGG pathway enrichment analysis based on the differentially expressed genes

a In early embryo development, $\mathbf{b}$ In the stage of embryo morphogenesis, $\mathbf{c}$ In shoot stage.

The longitudinal coordinates are the enriched KEGG Pathways, and the $\mathrm{x}$-axis monitors the rich factor; the size of the dots in the graph represents the number of differentially expressed genes annotated to the mentioned pathway, and the color represents the significant $P$ value of the pathway. The most significant pathways are shown in the picture.
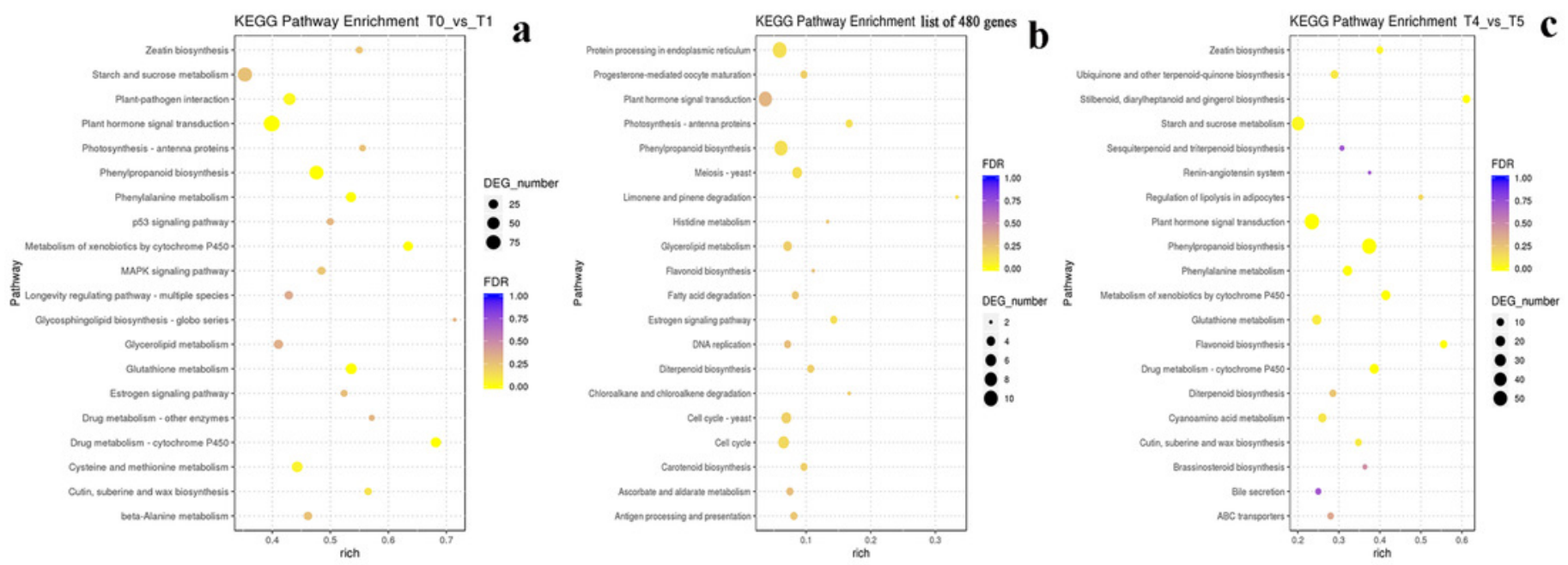


\section{Figure 7}

The matrix graph of upregulated expression genes in the plant hormone signal transduction pathway in six time points

The absolute values of the relative expression of upregulated genes were indicated by the depth of color. The $x$-axis of the matrix graph showed the six time points. The $y$-axis of the matrix graph showed the name of the upregulated genes. The upregulated genes were arrayed according to the hormonal signal transduction flows, which were classified into six groups: auxin, cytokinin, abscisic acid, ethylene, brassinosteroid, salicylic acid.

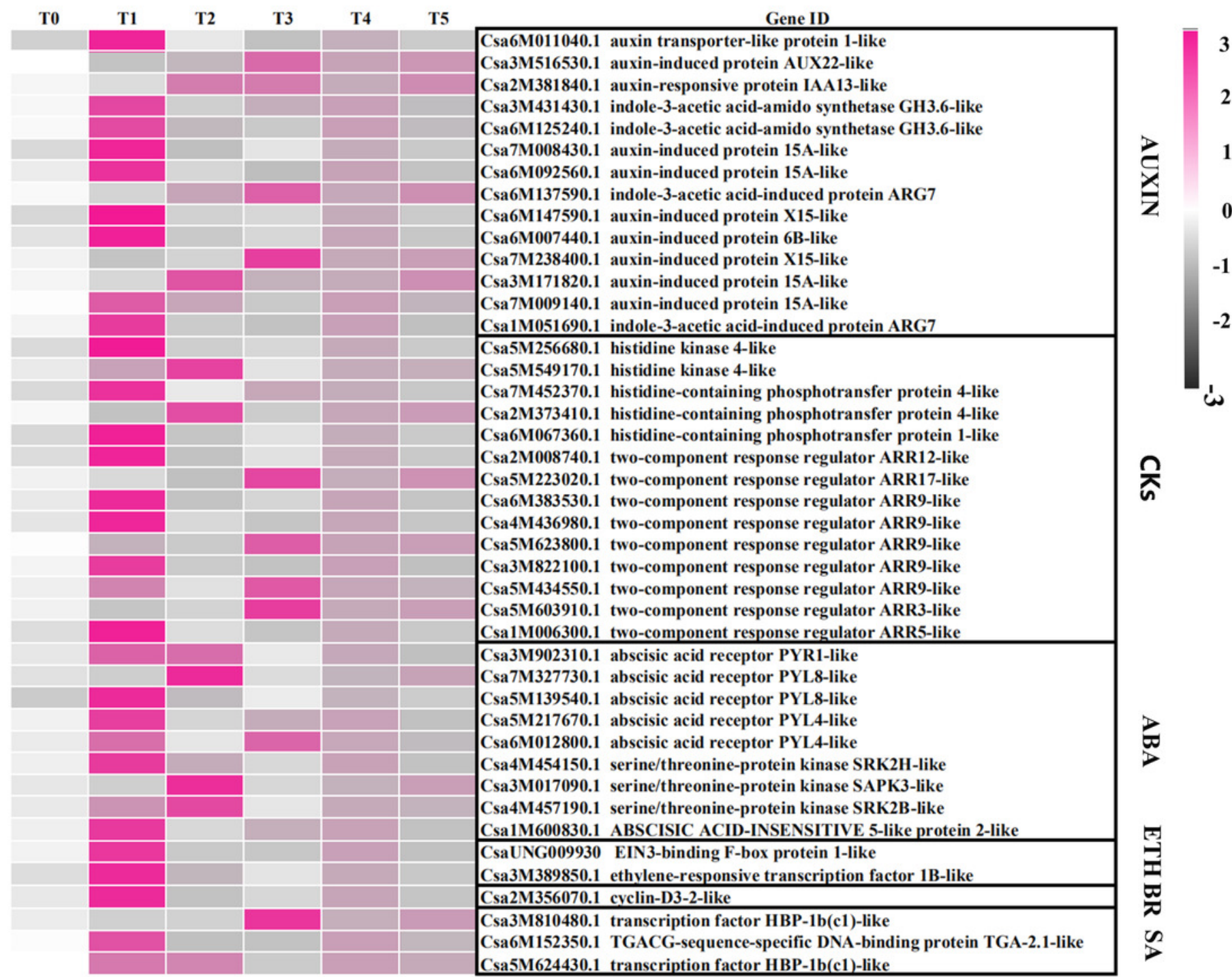


Figure 8

Venn diagram showed differentially expressed genes in the stage of embryo morphogenesis

The DEG sets (T1 vs T2, T2 vs T3 and T3 vs T4) described in Fig. 4 were analyzed using the Venn method. The numbers marked in the diagram indicated the number of genes significantly expressed among the three DEGs sets. 
T1_vs_T2

T2_vs_T3

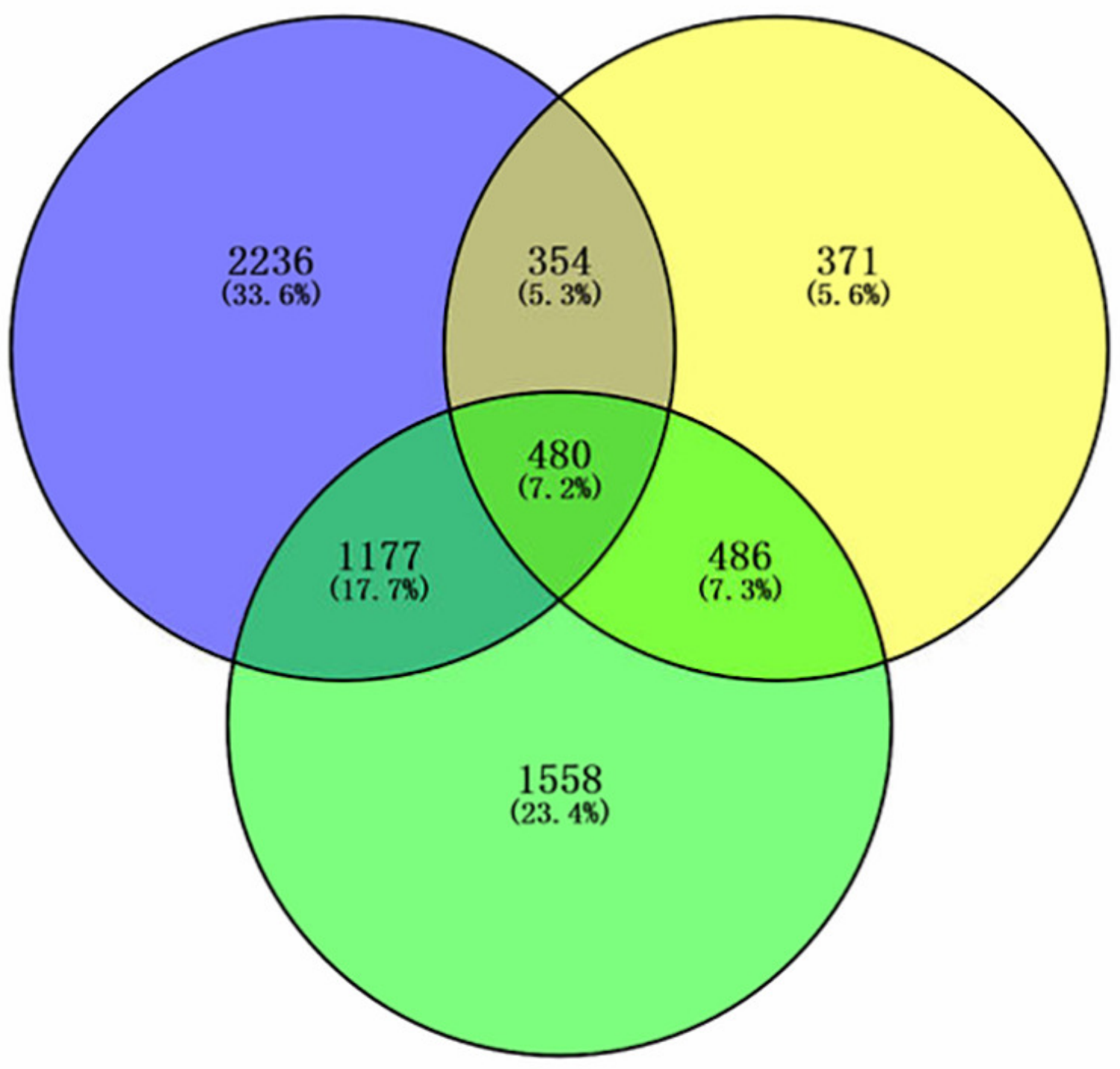

T3_vs_T4 